\title{
A VERY RARE CASE OF ISOLATED TETRA-AMELIA
}

\author{
Ankita Guptaํ, Naima Mannan², Usha Jaipal ${ }^{3}$ \\ ${ }^{1}$ Resident Doctor, Department of Radiodiagnosis, SMS Medical College, Jaipur. \\ 2 Professor, Department of Radiodiagnosis, SMS Medical College, Jaipur. \\ ${ }^{3}$ Senior Professor and HOD, Department of Radiodiagnosis, SMS Medical College, Jaipur.
}

\section{ABSTRACT}

\section{BACKGROUND}

We present an interesting case of an intrauterine diagnosed tetra-amelia foetus in a primigravida. The foetus was in 17 th week of the intrauterine life. There was no exposure to teratogenic agents in this pregnancy, although the patient gave a history of oral antibiotics intake for upper respiratory tract infection.

\section{MATERIALS AND METHODS}

A 23-year-old primigravid female came in to our institution for antenatal ultrasonography in her $17^{\text {th }}$ week of gestation. After antenatal diagnosis, late medical termination of pregnancy was undertaken.

\section{RESULTS}

Tetra-amelia is a very rare congenital anomaly, with an incidence of 1.5-4 per 100,000 births. It is defined as the complete absence of all four limbs which occurs as a result of developmental interruption between 24th and 36th days after fertilisation. It is presented as an isolated defect or can be also associated with other anomalies. In our case, the foetus was diagnosed with isolated tetra-amelia and other associated anomalies were absent.

\section{CONCLUSION}

Tetra-amelia could be seen as a syndrome or as an isolated case. Its aetiology and the mode of inheritance is still not clear. Syndromes that may be recognised with accompanying pathologies should be considered in evaluation of the patient. Karyotype analysis and genetic counselling should be always recommended.

\section{KEYWORDS}

Tetra-Amelia, Isolated.

HOW TO CITE THIS ARTICLE: Gupta A, Mannan N, Jaipal U. A very rare case of isolated tetra-amelia. J. Evolution Med. Dent. Sci. 2017;6(4):337-339, DOI: 10.14260/Jemds/2017/75

\section{BACKGROUND}

Tetra-amelia is a very rare congenital anomaly with an incidence of $1.5-4$ per 100,000 births. ${ }^{1}$ It is defined as the complete absence of all four limbs which occurs as a result of the developmental interruption between 24 th and 36th days after fertilisation. It is presented as an isolated defect or can be also associated with other anomalies.2,3 The clinical definition of the different anomalies related with tetra-amelia is not clear yet. ${ }^{4}$ We present an interesting case of an intrauterine diagnosed tetra-amelia foetus in a primigravida. The foetus was in 17th week of the intrauterine life. There was no exposure to teratogenic agents in this pregnancy, although the patient gave a history of oral antibiotics intake for upper respiratory tract infection.

\section{MATERIALS AND METHODS}

A 23-year-old primigravid female came in to our institution for antenatal ultrasonography in her $17^{\text {th }}$ week of gestation. After antenatal diagnosis, late medical termination of

Financial or Other, Competing Interest: None.

Submission 06-12-2016, Peer Review 30-12-2016,

Acceptance 06-01-2017, Published 12-01-2017.

Corresponding Author:

Dr. Ankita Gupta,

319, Nirman Nagar- AB,

King's Road,

Ajmer Road,

Jaipur (Raj) - 302019

E-mail: ankitagupta0312@gmail.com

DOI: $10.14260 /$ jemds $/ 2017 / 75$

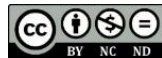

pregnancy was undertaken. The post-abortive specimen of foetus was analysed and a radiograph of aborted foetus was obtained.

\section{RESULTS}

A 23-year-old, primigravida woman was referred for antenatal ultrasonography at her 17 th gestational week. The spouse was a second degree blood relative. There was no history of exposure to teratogenic agents in this pregnancy. Ultrasonography analysis determined that biparietal diameter was 17 weeks 2 days. Head circumference was 17 weeks 3 days and abdominal circumference was 18 weeks 4 days. Upper and lower limbs were absent in the foetus in ultrasonography analysis. The family was offered the options of termination of pregnancy, karyotype analysis and genetic consultation. Family opted for late medical termination of pregnancy.

Tetra-amelia is a rare congenital defect which takes place between 24th and 36th day after fertilisation due to cessation of embryonic development. In most cases, its aetiology cannot be determined. It could be observed as a single case or as a part of genetic syndrome.1,2 In many cases, tetra-amelia was accompanied by several malformations such as lip and palate cleft, choanal atresia, cataract, absence of the nose, cranial malformation, microphthalmia, ocular coloboma, microcornea, absence of optic nerve, neural tube defect, single-or double-sided absence of the kidneys, absence of external genitalia, anal atresia, pulmonary hypoplasia, diaphragmatic hernia and absence of the pelvic bones. ${ }^{4}$ 
In our case, we detected isolated absence of all the four limbs without any other associated anomaly. Tetra-amelia can be also a part of several genetic syndromes such as Roberts syndrome, caudal regression syndrome, femoral hypoplasia-atypical facial syndrome, Baller-Gerold syndrome and Hermann-Pallister-Opitz syndrome. ${ }^{5}$ It has been shown that the cause of tetra-amelia is due to a defect in the WNT3 gene in Roberts syndrome. WNT3 gene, located at 17q21, regulates the development of the limbs and other organs. ${ }^{6}$

In the past, cases of tetra-amelia due to thalidomide use to treat hyperemesis on pregnant women were reported. ${ }^{7}$ In the literature, six tetra-amelia cases in the same family were reported by Zimmer et al. Since all tetra-amelia patients were male, it was called tetra-amelia syndrome due to $\mathrm{X}$ chromosome. Basaran et al described two patients with tetraamelia male infant accompanied by multiple anomalies. Both couples had one healthy daughter.

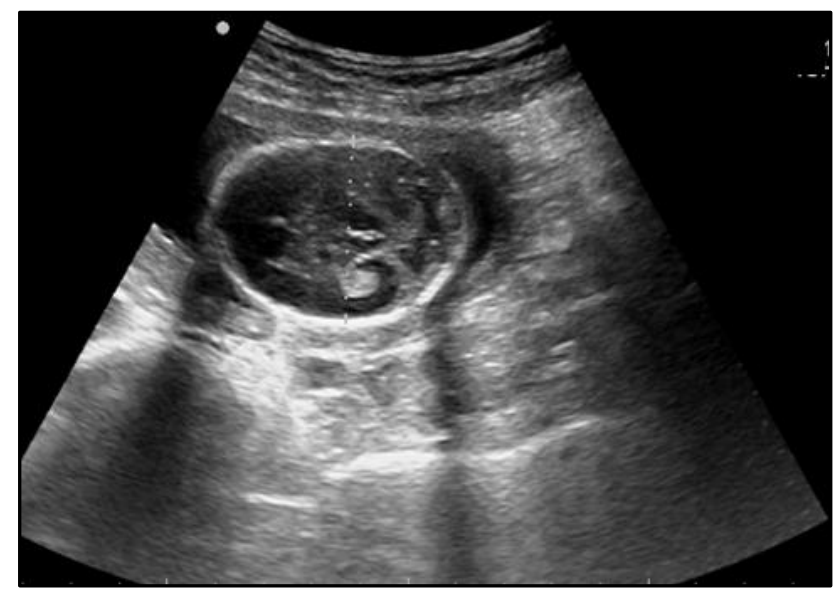

Figure 1. Ultrasonogram showing Biparietal Diameter of 17 weeks and 2 days

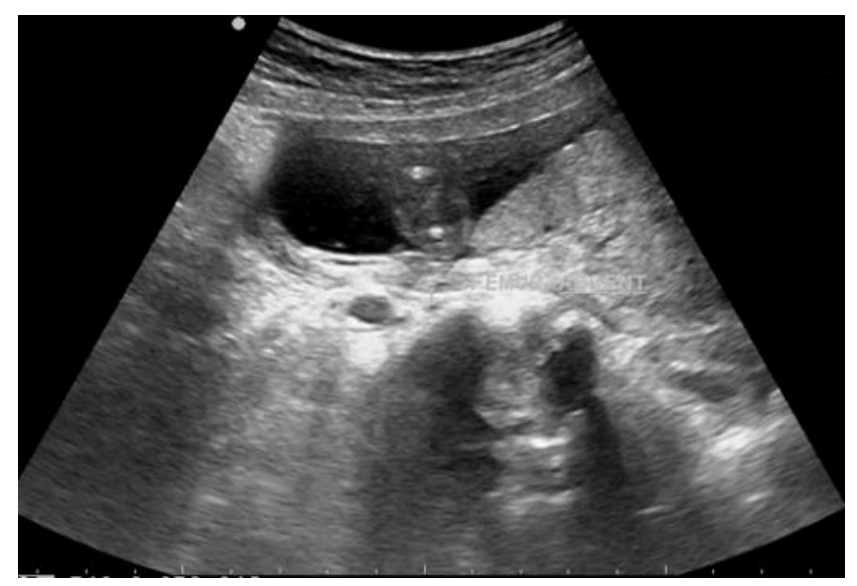

Figure 2. Ultrasonogram showing Absent Lower Limbs

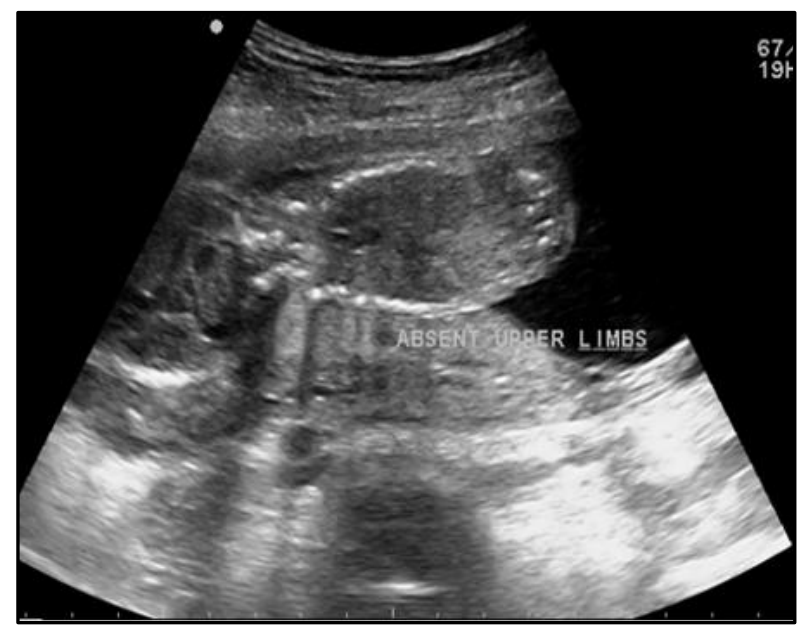

Figure 3. Ultrasonogram showing Absent Upper Limbs

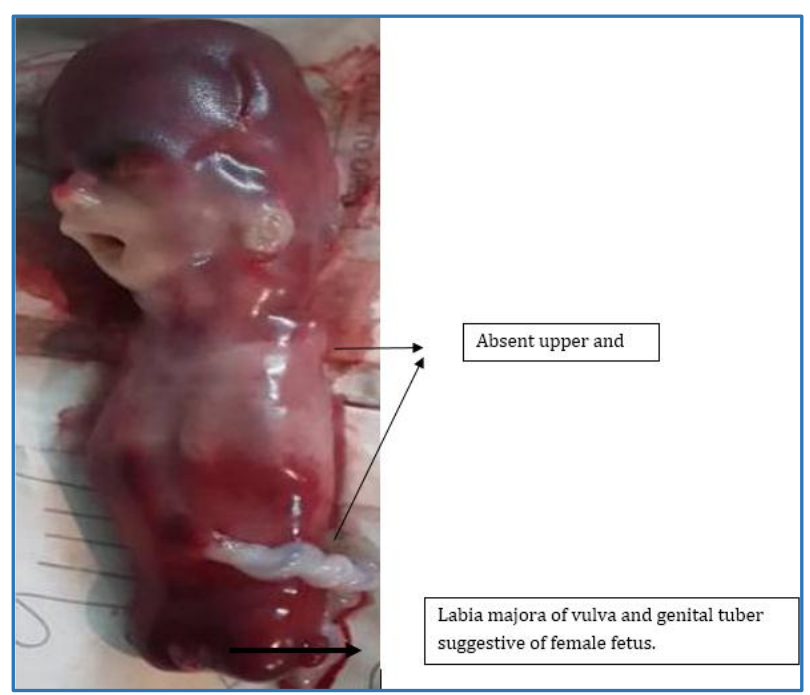

Figure 4. Post-abortive Specimen of Foetus

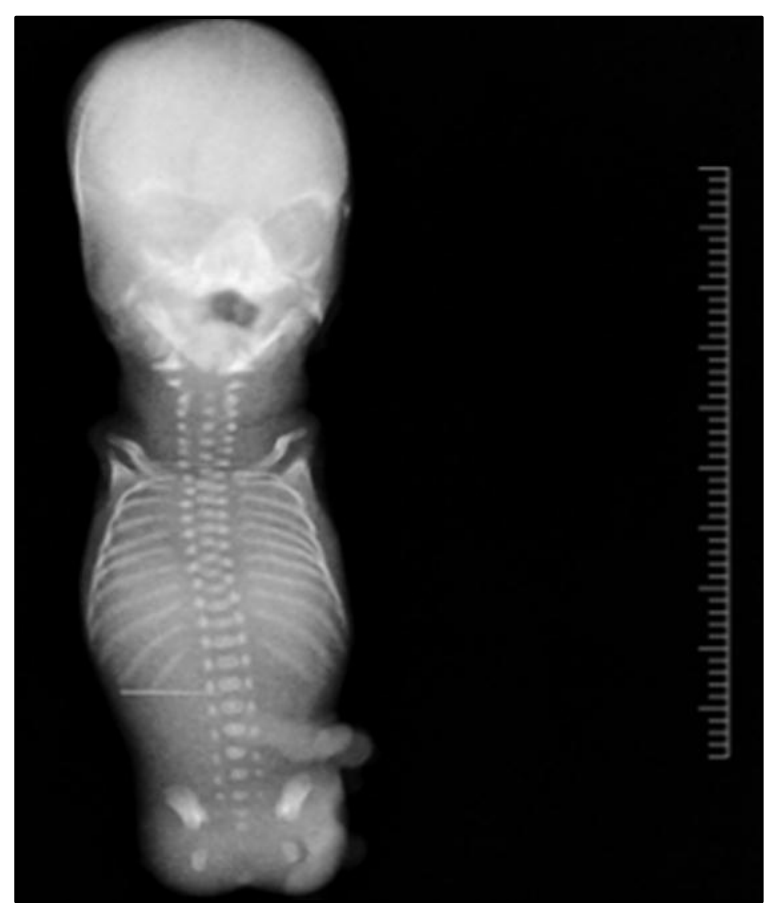

Figure 5. Radiograph of aborted Foetus showing Absent Bones of both Upper and Lower Limbs 


\section{CONCLUSION}

To conclude, tetra-amelia could be seen as a syndrome or as an isolated case. Its aetiology and the mode of inheritance is still not clear. There are different opinions about the genetic aspect of tetra-amelia. Syndromes that may be recognised with accompanying pathologies should be considered in evaluation of the patient. Karyotype analysis and genetic counselling should be recommended.

\section{Acknowledgements}

We thank Resident Doctors of Department of Obstetrics and Gynaecology for assistance in manuscript preparation.

\section{REFERENCES}

[1] Lenz W. Genetics and limb deficiencies. Clinical Orthopaedics Related Research 1980;148:9-17.

[2] Pierri NB, Lecora M, Passariello A, et al. New case of bilateral upper limb amelia, facial clefts, and renal hypoplasia. American Journal of Medical Genetics 2000;91(2):123-5.
[3] Kozin SH. Upper-extremity congenital anomalies. The Journal of Bone and Joint Surgery American 2003;85$A(8): 1564-76$.

[4] Sousa SB, Pina R, Ramos L, et al. Tetra-amelia and lung hypo/aplasia syndrome: new case report and review. American Journal of Medical Genetics 2008;146A(21):2799-803.

[5] Song SY, Chi JG. Tri-amelia and phocomelia with multiple malformations resembling Roberts syndrome in a fetus: is it a variant or a new syndrome? Clinical Genetics 1996;50(6):502-4.

[6] Niemann S, Zhao C, Pascu F, et al. Homozygous WNT3 mutation causes tetra-amelia in a large consanguineous family. American Journal of Human Genetics 2004;74(3):558-63.

[7] Smithells RW, Newman CG. Recognition of thalidomide defects. Journal of Medical Genetics 1992;29(10):71623. 